\title{
Adoption of Smart Grid Framework Which Tracks Power Consumption of Household Appliances in Zimbabwe
}

\author{
Elliot Mbunge ${ }^{1}$, Talent Rugube ${ }^{2}$ \\ ${ }^{1}$ Department of Information Technology, Faculty of Accounting and Informatics, Durban University of Technology, Durban, South Africa \\ ${ }^{2}$ Department of ICT and Electronics, Faculty of Science and Engineering, Chinhoyi University of Technology, Chinhoyi, Zimbabwe
}

Email address:

mbungeelliot@gmail.com(E.Mbunge),ttrugube@gmail.com(T. Rugube)

\section{To cite this article:}

Elliot Mbunge, Talent Rugube. Adoption of Smart Grid Framework Which Tracks Power Consumption of Household Appliances in Zimbabwe. American Journal of Operations Management and Information Systems. Vol. 3, No. 1, 2018, pp. 27-32.

doi: 10.11648/j.ajomis.20180301.14

Received: February 27, 2018; Accepted: March 13, 2018; Published: April 9, 2018

\begin{abstract}
The aim of this study was to design a smart grid framework which tracks power consumption of household appliances. The study explored technology being used with current traditional power grid to transmit and distribute electricity from power generation sources until power reaches the final consumer. The challenges and problems of the current traditional grid were unearthed in this study to bring best solution to mitigate the current power shortage problems. Smart grid model which supports real-time electricity power usage monitoring and controlling capability is proposed as an alternative measure to control unnecessary power usage for domestic and commercial purposes. Real-time power usage monitoring, distributed power generation, varying energy demand, remote detection and faults identification, and bi-directional communication are crosscutting technology and drivers of the implementation of smart grid. The researchers recommended energy authorities to engage with power customers to craft a policy that govern remote monitoring and controlling of electrical appliances' power consumption to ensure complete adoption of smart grid.
\end{abstract}

Keywords: Smart Grid, Smart Meters, Traditional Power Grid, Sustainable Energy Sources

\section{Introduction}

Smart grid refers to several technologies that use digital communications to coordinate a network of electricity delivery systems (Elyoenai, Daniel, Jairo, Victor, \& Luis, 2012). Digital commination technologies establish communication platform (Stuti, 2014) in bi-directional form between the electricity customers and power generation sources. The purpose of smart grid systems is to provide adaptable electricity infrastructure, and to optimise energy proficiency (Nicole \& Wesley, 2015). Currently, there are various existing power grid technologies, and each version of grid is unique in form and functions. Power grid systems have common goals which are to: reduce power consumption, monitor electricity usage during peak and offpeak times of day (Amir-Hamed, Vincent, Juri, Robert, \& Alberto, 2010), and to enable dynamic power distribution.

The increase of population and the high use of electrical gadgets in Zimbabwe triggered more demand on energy consumption. Power shortages have been on the rapid increase of late and affect the economy of Zimbabwe as the country's debt-laden power utility fails to sufficiently supply power to agriculture, commerce and industry (Tichaona, 2012). Energy crises worsen when Kariba Hydropower Station reduced its production capacity half below its operational level, thereby plunging the country into unsustainably load shedding (Phillimon, 2015). This precarious situation plunged industries especially in mining sector into spells of doom. The magnitude of power shortages shows that industries and households have to be content with inconveniences and costs associated with blackout. Residents are encouraged to switch off geysers and other electrical appliances which consumes more electricity to save $300 \mathrm{MW}$ but to no avail (Herald, 2015). There need for technology to detect and react to changes in electrical usage using remote control and an automation mechanisms (technological-aided assistant) is irresistible.

Power deficit has been affecting country's economic growth. Domestic and commercial industries, farming activities, healthcare facilities (hospitals and clinics), 
financial institutions, schools and universities are incurring extra cost of buying uninterrupted power supply and generators (Ndakaziva, 2017) to keep running. However, several companies failed to keep afloat and closed. Electricity customers also contribute to the scarcity by not switching off unused households appliances such as Television, geysers, heaters, computers or laptops, and electrified bathrooms. The use of geysers and electric water heaters was banned in Zimbabwe in year 2015 by electricity regulatory board (Herald, 2015) in move to save 400megawatts (British Broadcasting Corporation, 2015). People are encouraged to use solar powered geysers or water solar heating system. When switched on simultaneously, all geysers gobble $25 \%$ of electricity generated in the country (Techzim, 2013). It reflects that customer behavioural change also contributes significantly in saving electricity. However, customers are usually left out in the development and deployment electricity policies and strategic electricity saving plans but their participation and involvement could bring positive results.

Domestic customers' behavioral change is the key to realizing the benefits of smart grid technologies (Engerati, 2015). With smart grid, every stakeholder participates to directly or indirectly. All stakeholders must be engaged by the proponents of this technology to ensure full participation of everyone to develop tailored financial, environmental regulatory measures that facilitate the potential of smart grids. All stakeholders must be engaged by the proponents of this technology to ensure full participation of everyone to develop tailored financial, environmental regulatory measures that facilitate the potential of smart grids.

Smart meters have been installed since 2016 to improve electricity energy efficiency and to prepare for the implementation of smart grid (Felex, 2016). In this way, the "smart" components of the grid bring additional and valuable information to apply as electricity generation, distribution, and consumption are optimized. The availability of smart meters and Advanced Metering Infrastructure (AMI) makes it possible to read data about electricity consumption in realtime basis (Nico \& Kemal, 2013). AMI supports bidirectional communication between electricity consumers and utilities to enable dynamic response to power usage during peak time. Smart grid transmits electricity and data to facilitate efficient management of the grid, and integration of renewable energies from various electricity sources (Mathilde, 2013). Smart grid allows consumers within the same building to share electricity to enable stable supply of electricity. Eventually, this creates a network of networks in a smart grid.

\section{Related Work}

\subsection{Traditional Power Grid}

Traditional power grids are optimized for national and or regional power distribution. It distributes electricity from generation sources using high-voltage transmission lines that crisscross the substations to distribute power locally (John, Bartosz, Byron, \& Ilia, 2013). This architecture of power generation and distribution include; centralized energy plants that transmit power using electro-mechanical grid. In traditional power grid, there is no bi-directional communication between the grid and customers (Andre, Erwin, Wolfgang, \& Konstantina, 2014). With Traditional power grid, it is very difficult to dynamically distribute electricity during varying peak demand, and billing process is usually done manually (Jinju, Lina, Canbing, Yijia, Xubin, \& Yinghui, 2014).

\subsection{Motivation for Smart Grid Technology}

The world at large energy systems encounters many problems such as: integration of other electrical sources into electrical grid, varying and growth of electrical demands from end-users and regulatory authorities, generation of electricity using sustainable means and the need to increase security in Advanced Metering Infrastructure to avoid revenue leakages (Charles, 2013). Smart grid aims to provide electricity using more affordable, sustainable and efficient technologies instead of only providing measures to the problems above. Smart grid provides the following services over traditional grid: real- time monitoring of power consumption, bi-directional communication, and autonomous fault identification within a grid, ability to integrate energy generated from renewable and non-renewable sources, consumer participation and distribution intelligence. Distributed intelligence enables the grid to implement miniscule delays upon the delivery of electricity that relieves pressure and reduces the sudden increase in demand (Greenage). Smart Grid key market drivers are: the need for sustainable ways of generating electricity (Environmental concern), increased consumption of renewable energy (demand growth), avoidance of electricity leakages and theft (energy supply security), and aging infrastructure, information and data security, different renewable energy deployment is increasing rapidly.

\subsection{Technologies Involved in Smart Grid}

Smart grid technology is divided into five key areas:

\subsubsection{Integrated Communications}

To fully realize the functionalities of smart grid, communication technologies in smart grid and telecommunications companies need to be wholly integrated. Areas that need to be integrated are: distribution and substation automation, demand response, supervisory control and data acquisition (SCADA), power-line carrier communications, energy management systems, wireless mesh networks and fiber-optics ( Decision Interface, 2010). Integrated communications promote real-time monitoring and control, data and information interchange to enhance system reliability, infrastructure utilization, and smart grid security (Boris, 2011).

\subsubsection{Measurement and Sensing}

Main responsibilities of sensors in a smart grid are: to maintain grid stability, monitoring grid infrastructure, to prevent electricity theft (Boris, 2011). Smart grid innovations include: digital protective relays, Advanced Metering Infrastructure (smart meter), remote control systems, 
dynamic line rating, electromagnetic signature analysis and measurement, time-of-use and real-time electricity pricing, meter reading equipment, backscatter radio technology (Richard, 2008).

\subsubsection{Smart Meters}

Smart meter records electricity usage on real-time basis and also enable communication channel between power generation plants to smart socket and other smart grid-aided devices (Charles, 2013). Due to consumer's choice, such equipment can be turned-off during moments of peak demand.

\subsubsection{Phasor Measurement Units (PMUs)}

PMUs are sensors which are distributed throughout the network and are used to monitor power quality and automatically give feedback to Smart grid. Phasors are waveforms of alternating current which are distributed in real-time and are similar in shape everywhere throughout the network (Sebnem, Kolja, \& Christoph, 2010).

\subsubsection{Advanced Control}

Power system automation enables controlling the system via automated procedures using intelligent integrated circuits devices and computers (Neil, Valeriy, \& Karlheinz, 2010). It also aids in efficiency diagnosis of smart grid faults and disruptions. Techniques that are involved in advanced control system are: analytical tools (high processing machines and software algorithms), distributed intelligent agents (monitoring and control systems), and operational applications (substation automation, supervisory control and data acquisition, demand response) (Boris, 2011). In China, Fujian power grid used artificial intelligent to develop protection system which is able to calculate a control strategy and execute it (Jinquan, Wenying, Zhaoxiong, Feng, Kewen, \& Yong, 2007). Optimal control strategy is determined by linear programming techniques.

\subsubsection{Decision Support and Better Interface}

Technologies that assist smart grid managers and operators to reduce operational complexity due to dynamic change variables are: visualization techniques and software systems for decision support purpose and simulators are used for analysis, provision of better user interface and training purpose (Neil, Valeriy, \& Karlheinz, 2010).

\section{Methodology}

\subsection{Smart Design Framework}

The design process was done in three phases:

(i) Identification and ordering of the various steps in adoption.

(ii) Identification of key-pillars of Smart grid.

(iii)Identification of crucial smart grid stakeholders and variables.

Thus, researchers used an incremental approach to the design the smart grid framework. The design was targeted at achieving the following: identification of electrical appliances which consume more unnecessary power and control it, real-time remote monitoring of power consumption, sustainable use of power from sustainable sources (Go Green power sources) and power saving.

\subsection{The Six-Steps of Adoption Process}

\subsubsection{Pre-adoption}

The starting point is to get individuals or organizations interested in the Smart grid to be involved in the setting of goals and objectives of the development and implementation of smart grid. This step aims at taking individuals from what they understand and preparing or guiding them towards a thinking process needful for a successful adoption of smart grid. There has to be crisp understanding of power generation sources (renewable and non-renewable) which are environmentally sustainable. The areas of interest at this stage are; Power network, solar supply, water supply, thermal supply. All these power generations have to be integrated together to feed power into a smart grid (bulk power generation) to increase power output.

\subsubsection{Assessment and Alignment}

With clear goals and objectives, it is easy to assess the shortfalls of the current traditional grid technology against the strength of the proposed technology (smart grid) in solving the current power shortages. The purpose of this stage is to ensure that the identified technologies will indeed assist in the achievement of the set goals and objectives. Integration of ICTs solutions, security, current power infrastructure and utilities need proper alignment to achieve the set goals and objectives.

\subsubsection{Involvement}

This stage involves all stakeholders that have direct interest in the implementation of smart grid. Rope in relevant stakeholders such as community, power companies, telecoms companies, ICT companies, environmental management authority, parliamentarians, traditional leaders, NonGovernmental Organizations in the process of implementing smart grid reduces resistance to adopt smart grid.

\subsubsection{Influence}

The major step that enables adoption of smart grid is to involve right people and organizations that will assist in the achievement of the set goals and objectives. Though the initiator may pretty-well understand and able to adopt to smart grid, it will take participation of all stakeholders at large for the achievement of a Smart Grid. Regulatory authorities and policy makers must play a role to increase awareness and encourage people to adapt to smart grid technologies.

\subsubsection{Development and Implementation}

Once all stakeholders have been roped in and the government has given its buy-in, the next move is to develop and implement smart grid. Interoperability of utilities and operations must be carefully observed at this stage. Most crucial activities at this stage are; development of power renewable and non- renewable power plants, upgrade and maintenance of existing power plants, parliamentarians to influence the implementation of Smart grid. 


\subsubsection{Evaluation}

Interoperability, standards and protocols of infrastructure and utilities must be evaluated to check performance of the smart infrastructures. Integrated devices they have unique protocols, so interoperability must be carefully assessed. There is also a need to assess whether the implemented technology addresses the initially set goals and objectives.

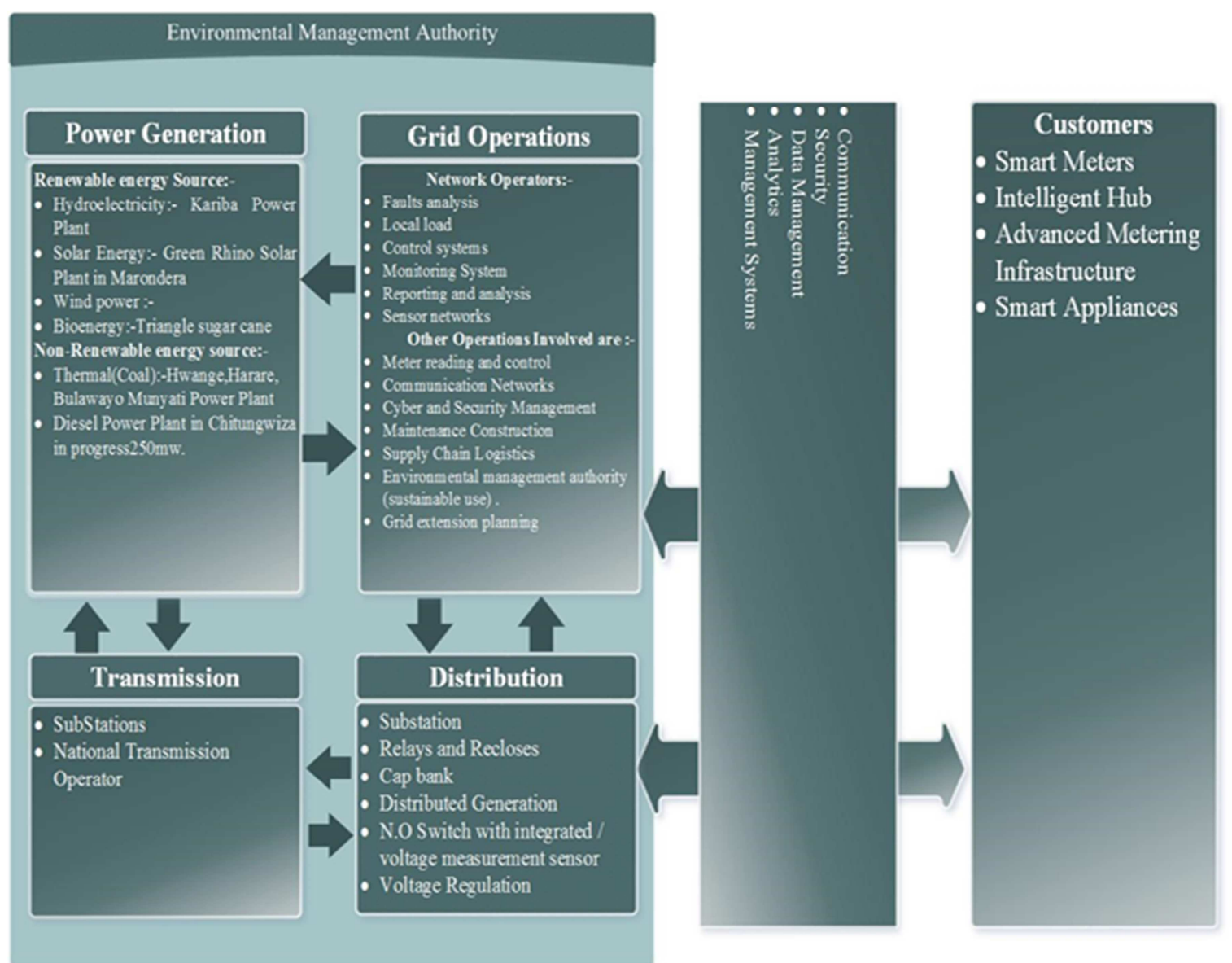

Figure 1. Proposed Smart grid framework.

\section{Proposed Smart Grid Framework}

\subsection{Power Generation}

Power generation from renewable and non-renewable sources is typically the initial stage in the delivery and distribution of electricity to consumers. Power generation include series of activities to produce electricity from different types of energy, which vary from flowing water, solar radiation, bioenergy and thermal energy. Power generation activities are connected to Operations and Transmission stages. The benefit of Power generation from the setting out of smart grid is the capability of mechanically reroute electricity flow from one grid to the other grid when generators malfunction.

\subsection{Electricity Transmission}

Electricity Transmission involves bulk transmission of power from power generation (renewable and non-renewable sources) to distribution through several electricity substations. Transmission phase is connected to Distribution phase and Power Generation as well as interacting with
Operations. Independent System Operator usually operates electricity transmission network to maintain stability by creating a balance between varying load demand with supply in the smart grid.

Actors at this phase involve fault recorders, protection relays, remote terminal units, power quality monitors, substation meters, phasor measurement units, sag monitors and substation user interfaces (Enernex, 2011).

\subsection{Electricity Distribution}

Electricity Distribution phase connects, Operations, Electricity Transmission phase and Consumer phase at the metering points for power consumption. Historically, Communications interfaces within this phase are hierarchical and unidirectional (Enernex, 2011). Technological innovation of varying energy demand response, power distributed storage, distributed power generation, and load control has increased the capabilities of the Customer phase to increase the reliability of Electricity Distribution phase.

Features such as; wide monitoring, interconnection, smart control devices and distributed energy resources which are able to store and generating electricity are found in 
Distribution network. Such Distribution networks have the ability to self-support "micro-grids", when electrical fault happens consumers could not even notice it. Devices that are involved at this phase are; storage devices, sectionalizers, electrical capacitor banks, protection relays, reclosers and distributed generators.

\subsection{Operations}

Operations phase involves a series of activities that perform day-to-day management roles necessary for effective and efficient operation of the electricity system from power generation to consumers. Some of the activities that are involved in the Operations are: fault management, network operation, network control and monitoring, operation feedback analysis, real-time network calculation, operational statistics and reporting, dispatcher training. Above all mentioned activities, environmental management authority oversees all Operations activities to ensure that the environment is conserved in a sustainable way.

\subsection{Electricity Consumers}

The Customer domain is electrically connected to the Distribution domain. It communicates with the Distribution, Operations, Markets, and Service Provider domains. Devices in the Consumer phase enable consumers to monitor and manage domestic and industrial electrical usage. Such devices also enable bi-directional communication and control information flow between energy consumer and other phases. Three categories of electricity consumers within the Consumer phase are; building offices, industrials (heavy and light), and home (domestic use). Power demand for these three customers varies with respect to their electricity usage and goals. Devices at customer phase include gateway (intelligent hub), smart meters and Advanced Metering Interface.

\subsection{Intelligent $\mathrm{Hub}$}

It enables remote load monitoring and control, in-home electricity usage display, identification and recognition of electrical appliances' electivity consumption via management system. Intelligent hub (gateway) has the capacity to enforce auditing and logging. Intelligent hub is introduced due to the fact there are various smart grid technologies and implementation strategies for new equipment but no standardized protocols have yet defined. At each household stage, an intelligent hub is connected through smart metering system to substation to enable to communicate with electrical customer. This connectivity enables intelligent hub to simulate the behavior of electrical appliance's power consumption through the use of sensors and actuators. Intelligent hub links logical and physical layer of the smart grid and gather data from both layer. Data acquisition is done by sensors. Types of data include assessing units on the power lines. Actuators interact with smart grid to perform tasks such as varying power load demand control. This improves security in a smart grid.

\section{Conclusion}

\subsection{Increase Various Alternative Power Generations Sources}

Government authorities have to increase electricity from various power generation sources such as renewable and norenewable energy. For improved reliable electricity supply, there is an immediate need for increasing and build new power plants using energy sources such as hydro power, gas, solar energy, biomass, coal and diesel power plant. These power plants can be built through public-private partnerships.

\subsection{Implementation of Smart Grid}

Smart Grids aim to provide electricity using more affordable, sustainable and efficient technologies. The world at large energy systems encounters many problems such as: integration of other electrical sources into electrical grid, varying and growth of electrical demands from end-users and regulatory authorities, generation of electricity using sustainable means and the need to increase security in Advanced Metering Infrastructure to avoid revenue leakages (Charles, 2013). Smart grid is ideal to mitigate all the challenges mentioned above. Smart grid has the ability to monitor electricity consumption on real-time, respond to varying load demand, bi-directional communication between electrical gadgets and smart grid, immediate detection of faults on the grid from generation sources (transmission, distribution) to the consumers

\subsection{Legislation and Policies}

Despite the government's initiation to generate power from renewable energy sources such as solar, hydro and biomass in the nation's energy generation sources but there is no supporting legislation and policies that guide such initiations. Information Communication Technology (ICT) has to be involved in the implementation of Smart grids through the use innovative utilities and ICT applications in the production and distribution electricity to consumers. There is need to draft ICT policies that are ahead of current trends in the country. The ICT policy should facilitate the adoption and implementation of newer technologies as compared to just improvement of already existing technologies. Environmental management authority must also play a role in the energy production since they are the ones who monitor and manage all renewable and non- renewable energy sources to ensure that all power production are done in using environmental sustainable way. There has to be an environmental policy that governs energy productions. In light of that power production should involve and integrate various cross-cutting technologies, Ministries and different government authorities. This calls for great synergy.

\subsection{Community Engagement and Involvement}

It involves all community stakeholders that have direct and indirect interest in the implementation of smart grid. Awareness campaigns are needed to educate the community 
on the importance of being a responsible electricity user (customer). From the findings it shows that some of the electricity customers either for domestic use or commercial use are completely against the idea of remote monitoring of electrical appliances power consumption. Thus, communities must be educated that power saving initiation is everyone's' business not for the regulatory board only.

\subsection{Further Research}

The research was focused on the adoption of smart grid framework which tracks power consumption of household appliances in Zimbabwe. Further research may focus on cyber security issues associated with international implementation of Smart grid.

\section{References}

[1] Egozcue Elyoenai, Herreras, Rodríguez Daniel, Alonso, Ortiz Jairo, Fidalgo, Villar Victor, and Tarrafeta Luis. (2012, June) 'Smart Grid Security: Recommendations for Europe and Member States. [Online].

https://www.enisa.europa.eu/topics/critical-informationinfrastructures-and-services/smart-grids/smart-grids-andsmart-metering/ict-inderdependencies-of-the-smart-grid

[2] Ramola Stuti, "Digital Communication-Technology and Advancements," Advance in Electronic and Electric Engineering, vol. 4, no. 4, pp. 367-374, 2014.

[3] Sintov Nicole and Schultz Wesley, "Unlocking the potential of smart grid technologies with behavioral science," Frontiers in Psychology, vol. 6, no. 10, April 2015.

[4] Mohsenian-Rad Amir-Hamed, Wong Vincent, Jatskevich Juri, Schober Robert, and Leon-Garcia Alberto, "Autonomous DemandSide Management Based on Game-Theoretic Energy Consumption Scheduling for the Future Smart Grid," IEEE TRANSACTIONS ON SMART GRID, vol. 1, no. 3, December 2010.

[5] Zindoga Tichaona. (2012, January) Zimbabwe: Sengwa Power Project Still in Limbo. [Online].

http://allafrica.com/stories/201201130190.html

[6] Mhlanga Phillimon. (2015, September) Financialgazette. [Online]. http://www.financialgazette.co.zw/zimbabweelectricity-crisis-to-worsen/

[7] Herald. (2015, September) Herald. [Online]. https://www.herald.co.zw/geyser-ban-to-save-300mw/

[8] Majaka Ndakaziva. (2017, July) Dailynews. [Online]. https://www.dailynews.co.zw/articles/2017/07/20/cripplingpower-cuts-looming

[9] British Broadcasting Corporation. (2015, October) Zimbabwe to ban electric water heaters to save power. [Online]. http://www.bbc.com/news/world-africa-34416210

[10] Techzim. (2013, August) The mystery of ZESA bills/power cuts: an alternative solution. [Online]. https://www.techzim.co.zw/2013/08/the-mystery-of-zesabillspower-cuts-an-alternative-solution/

[11] Engerati. (2015, June) Zimbabwe Leads The 'Smart' Pack. [Online]. https://www.engerati.com/article/zimbabwe-leads\%E2\%80\%98smart\%E2\%80\%99-pack
[12] Share Felex. (2016, January) Smart metering the way to go. [Online]. https://www.herald.co.zw/smart-metering-the-wayto-go/

[13] Saputro Nico and Akkaya Kemal, "On preserving user privacy in Smart Grid advanced metering infrastructure applications," Wiley Online Library, vol. 7, no. 1, pp. 206-220, January 2013.

[14] Bonneau Mathilde. (2013, January) ICT's Role in Sustainability, the Case of Smart Grids: Potential and Challenges. [Online]. http://www.nouvelle-europe.eu/en/ict-srole-sustainability-case-smart-grids-potential-and-challenges.

[15] McDonald John, Wojszczyk Bartosz, Flynn Byron, and Voloh Ilia. (2013) Distribution Systems, Substations, and Integration of Distributed Generation. [Online].

https://pdfs.semanticscholar.org/eb74/ec02e8f7da50b7a8e5af0 0d97d59f8860349.pdf

[16] Richte Andre, van der Laan Erwin, Ketter Wolfgang, and Valogianni Konstantina. (2014) Transitioning from the traditional to the smart grid:Lessons learned from closed-loop supply chains. [Online].

http://powertac.org/sites/default/files/SG-TEP_Cameraready_version.pdf

[17] Zhou Jinju et al., "What's the difference between traditional power grid and smart grid? - From dispatching perspective," IEEExplore, June 2014.

[18] Mozina Charles, "Impact of Smart Grids and Green Power Generation on Distribution Systems," IEEE, vol. 49, no. 3, pp. 1079 - 1090, March 2013.

[19] Greenage. The smart grid. [Online]. https://www.thegreenage.co.uk/tech/features-of-smart-grid/

[20] Decision Interface. (2010, November) Smart Grid Features and Functions. [Online].

http://decisioninterface.blogspot.com/2010/11/smart-gridfeatures-and-functions.html

[21] Kuslitskiy Boris. (2011, November) Smart Grid Features. [Online]. https://blog.ansi.org/2011/11/smart-grid-features/

[22] Brown Richard, "Impact of Smart Grid on distribution system design," in Power and Energy Society General Meeting Conversion and Delivery of Electrical Energy in the 21st Century, 2008 IEEE, Pittsburgh, August 2008.

[23] Rusitschka Sebnem, Eger Kolja, and Gerdes Christoph, "Smart Grid Data Cloud: A Model for Utilizing Cloud Computing in the Smart Grid Domain," in Smart Grid Communications (SmartGridComm), 2010 First IEEE International Conference on, Gaithersburg, 2010.

[24] Higgins Neil, Vyatkin Valeriy, and Schwarz Karlheinz, "Distributed Power System Automation With IEC 61850, IEC 61499, and Intelligent Control," IEEE, vol. 41, no. 1, pp. 8192, April 2010.

[25] Zhao Jinquan et al., "On-Line Voltage Stability Monitoring and Control (VSMC) System in Fujian power grid," in Power Engineering Society General Meeting, 2007. IEEE, Tampa, July 2007.

[26] Enernex. (2011, November) A SMART GRID PICTURE IS WORTH A THOUSAND VIEWPOINTS. [Online]. http://www.enernex.com/archives/a-smart-grid-picture-isworth-a-thousand-viewpoints/ 